University of Nebraska - Lincoln

DigitalCommons@University of Nebraska - Lincoln

2005

\title{
Multi-platform comparisons of MODIS and AVHRR normalized difference vegetation index data
}

\author{
Kevin P. Gallo \\ National Climatic Data Center, Kevin.P.Gallo@noaa.gov \\ Lei Ji \\ Colorado St. University \\ Brad Reed \\ USGS/EROS, reed@usgs.gov \\ Jeffrey Eidenshink \\ USGS/EROS \\ John Dwyer \\ USGS/EROS
}

Follow this and additional works at: https://digitalcommons.unl.edu/natrespapers

Part of the Natural Resources and Conservation Commons

Gallo, Kevin P.; Ji, Lei; Reed, Brad; Eidenshink, Jeffrey; and Dwyer, John, "Multi-platform comparisons of MODIS and AVHRR normalized difference vegetation index data" (2005). Papers in Natural Resources. 195.

https://digitalcommons.unl.edu/natrespapers/195

This Article is brought to you for free and open access by the Natural Resources, School of at DigitalCommons@University of Nebraska - Lincoln. It has been accepted for inclusion in Papers in Natural Resources by an authorized administrator of DigitalCommons@University of Nebraska - Lincoln. 


\title{
Multi-platform comparisons of MODIS and AVHRR normalized difference vegetation index data
}

\author{
Kevin Gallo ${ }^{\mathrm{a}, *, 1}$, Lei Ji ${ }^{\mathrm{b}, 1}$, Brad Reed ${ }^{\mathrm{c}}$, Jeffery Eidenshink ${ }^{\mathrm{d}}$, John Dwyer ${ }^{\mathrm{c}}$ \\ a NOAA/NESDIS, Camp Springs, MD 20746, United States \\ ${ }^{\mathrm{b}}$ CIRA, Colorado St. University, Ft. Collins, CO 80525, United States \\ c SAIC, USGS/EROS, Sioux Falls, SD 57198, United States \\ ${ }^{\mathrm{d}}$ USGS/EROS, Sioux Falls, SD 57198, United States
}

Received 24 November 2004; received in revised form 30 August 2005; accepted 31 August 2005

\begin{abstract}
The relationship between AVHRR-derived normalized difference vegetation index (NDVI) values and those of future sensors is critical to continued long-term monitoring of land surface properties. The follow-on operational sensor to the AVHRR, the Visible/Infrared Imager/ Radiometer Suite (VIIRS), will be very similar to the NASA Earth Observing System's Moderate Resolution Imaging Spectroradiometer (MODIS) sensor. NDVI data derived from visible and near-infrared data acquired by the MODIS (Terra and Aqua platforms) and AVHRR (NOAA-16 and NOAA-17) sensors were compared over the same time periods and a variety of land cover classes within the conterminous United States. The results indicate that the 16-day composite NDVI values are quite similar over the composite intervals of 2002 and 2003 , and linear relationships exist between the NDVI values from the various sensors. The composite AVHRR NDVI data included water and cloud masks and adjustments for water vapor as did the MODIS NDVI data. When analyzed over a variety of land cover types and composite intervals, the AVHRR derived NDVI data were associated with $89 \%$ or more of the variation in the MODIS NDVI values. The results suggest that it may be possible to successfully reprocess historical AVHRR data sets to provide continuity of NDVI products through future sensor systems.
\end{abstract}

(C) 2005 Elsevier Inc. All rights reserved.

Keywords: AVHRR; MODIS; VIIRS; Normalized difference vegetation index; Composite; Data continuity

\section{Introduction}

Normalized difference vegetation index (NDVI) products are routinely produced from visible and near-infrared (NIR) data acquired by the NOAA series of Advanced Very High Resolution Radiometer (AVHRR) sensors. A number of studies (e.g., Kogan, 1997; Myneni et al., 1998; Nemani et al., 2003; Potter et al., 2003; Tucker et al., 2001; Zhou et al., 2001) have utilized the near 20-year historically available AVHRR data to monitor changes in vegetation activity and other land surface properties. The follow-on operational sensor to the AVHRR, the Visible/Infrared Imager/Radiometer Suite (VIIRS), will be very similar to the NASA Earth Observing System's Moderate Resolution Imaging Spectroradiometer (MODIS) sensor. Un-

\footnotetext{
* Corresponding author.

E-mail address: kgallo@usgs.gov (K. Gallo).

${ }^{1}$ Visiting scientist at USGS National Center for Earth Resources Observation and Science (EROS), Sioux Falls, SD 57198, United States.
}

derstanding the relationship between the AVHRR-derived NDVI and NDVI derived from other current and future sensors is critical to continued long-term monitoring of land surface properties such as those included in the studies cited above.

The bandwidths and spectral response associated with the red and NIR data used to compute NDVI differ for the MODIS and AVHRR sensors. The MODIS red (nominally 620 to 670 $\mathrm{nm}$ ) and NIR (841 to $876 \mathrm{~nm}$ ) bands are much narrower than the AVHRR red (585 to $680 \mathrm{~nm}$ ) and NIR (730 to $980 \mathrm{~nm}$ ) bands. Gitelson \& Kaufman (1998) compared of NDVI values simulated from the MODIS and AVHRR red and NIR bands and found slightly greater NDVI values from MODIS than those from AVHRR for a variety of plant chlorophyll content levels. Gao et al. (2003) compared MODIS composite NDVI values with single date NDVI values from several sensors (AVHRR not included) and found good agreement in response to phenology of the land cover types examined. Several studies have compared observed or simulated MODIS and AVHRR NDVI values (e.g., Fresholt, 2004; Huete et al., 2002; Steven et 
al., 2003; Trishchenko et al., 2002; Venturini et al., 2004) with mixed results that will be discussed later. Gallo et al. (2004) provided a cursory evaluation of a single year (2001) of Terra MODIS NDVI 16-day composites with NOAA-16 AVHRR 16-day composites that were corrected for water vapor, ozone, and Rayleigh scattering, and found good agreement between the NDVI values. Since that evaluation a new AVHRR data set has been made available that includes identification of cloud contaminated data. The objectives of this study were to expand the analysis of Gallo et al. (2004) and compare MODIS and AVHRR NDVI data sets for additional sensors (Aqua MODIS and NOAA-17 AVHRR), with additional ancillary data (AVHRR cloud contamination) over additional coincident time intervals (more than the one year examined in Gallo et al., 2004).

\section{Methodology}

\subsection{AVHRR data management}

AVHRR data were processed at the USGS National Center for Earth Resources Observations and Science (EROS) for the years of 2002 and 2003 for 16-day composite intervals that matched MODIS composite intervals. The AVHRR data were processed similar to the 2001 data used and described by Gallo et al. (2004). This $1-\mathrm{km}$ resolution AVHRR product includes corrections for water vapor (Defelice et al., 2003), ozone absorption, and Rayleigh scattering.

The corrections for ozone absorption and Rayleigh scattering are based on those described in Teillet (1991). The correction for ozone absorption is based on concentration values derived from the Total Ozone Mapping Spectrometer (TOMS), or when unavailable, other appropriate sensors (El Saleous et al., 1994).

Calibration coefficients were used for the NOAA-16 sensor as recommended by NOAA (see http://noaasis.noaa.gov/ NOAASIS/ml/n16calup.html). NOAA-17 calibration included postlaunch coefficients recommended by NOAA (see http:// www.osdpd.noaa.gov/PSB/PPP/notices/notices.html). The postlaunch coefficients were first released during May 2004. The calibration coefficients were estimated back through the start of use of NOAA-17 data in this study (1 January 2003) through a regression-based extrapolation of these coefficients, based on the number of days since sensor launch.

While the Gallo et al. (2004) analysis relied on the composite process to provide cloud-free comparisons of MODIS and AVHRR data, this analysis includes an AVHRR data set that includes identification of potential cloud contaminated data, which were subsequently excluded from the analysis. The cloud contaminated pixels within the AVHRR data used in this analysis were identified through the use of the Clouds from AVHRR (CLAVR) algorithms (Stowe et al., 1999; see also http://cimss.ssec.wisc.edu/clavr/). The spatial analysis algorithms included in CLAVR were not used in this study because the CLAVR algorithms were applied to composite AVHRR data rather than single scene data.

\subsection{MODIS data management}

The MODIS 16-day NDVI product (MOD13A2; Version 4) was used in this study (see http://pdaac2.usgs.gov/modis/ mod13a2v4.asp). The $1-\mathrm{km}$ resolution MODIS data are available with corrections for atmospheric gasses and aerosols using either other MODIS derived products or ancillary data (see http://modis-sr.ltdri.org/MOD09ProductInfo/User\% 27sGuideMOD09_L2.htm). The MODIS data were reprojected from the Sinusoidal projection to the Lambert Azimuthal Equal Area projection of the AVHRR data set using a nearest neighbor algorithm to preserve the quality assurance (QA) data that included the cloud condition information. The reprojected MODIS data, originally in 10 by $10^{\circ}$ tiles, were mapped into a seamless product for the conterminous United States, to match the available AVHRR products. The available QA information was used to identify those pixels that were cloud contaminated in the MODIS data set. Although the influence of cloud shadows on individual pixels is also available from the MODIS QA data this information was not used in this analysis as similar information is not available in the AVHRR data set. Pixels identified as cloud contaminated in a composite interval, within either the MODIS or AVHRR data sets, were excluded from the analysis for that interval.

\subsection{NDVI data analysis}

One of the differences between the MODIS and AVHRR NDVI products used in this study included an adjustment for the influence of aerosols applied to the MODIS data, but not the AVHRR data. Additionally, the NDVI composite techniques are different. The MODIS composite technique (constrained-view angle-maximum value composite) includes determination of the two greatest NDVI values per 16-day composite interval for each pixel, after screening of data based on QA and ancillary information (K. Didan, personal communication). The NDVI value observed with the nearest to nadir view is then included in the composite product (see http:// tbrs.arizona.edu/project/MODIS/compositing.php). The AVHRR composite technique (maximum value composite) simply selects the greatest NDVI value observed for each pixel per 16-day composite interval, although the solar zenith angle must be less than $80^{\circ}$.

Data from the Terra and Aqua MODIS sensors were used in this study, with equator crossing times (ECT, Table 1) of approximately 10:35 AM local standard time (LST) and 1:30

Table 1

Platform, equator crossing time (ECT), and 16-day NDVI composite data analyzed for 2002 and 2003

\begin{tabular}{llll}
\hline Platform & ECT & \multicolumn{2}{l}{ Data analyzed } \\
\cline { 3 - 4 } & & 2002 & 2003 \\
\hline NOAA-16 & $2: 00 \mathrm{PM}$ & 1 Jan-31 Dec & 1 Jan-12 Sep \\
NOAA-17 & $10: 15 \mathrm{AM}$ & & $1 \mathrm{Jan}-31 \mathrm{Dec}$ \\
Terra & $10: 35 \mathrm{AM}$ & $1 \mathrm{Jan}-31 \mathrm{Dec}$ & 1 Jan-31 Dec \\
Aqua & $1: 30 \mathrm{PM}$ & & $1 \mathrm{Jan}-31 \mathrm{Dec}$ \\
\hline
\end{tabular}




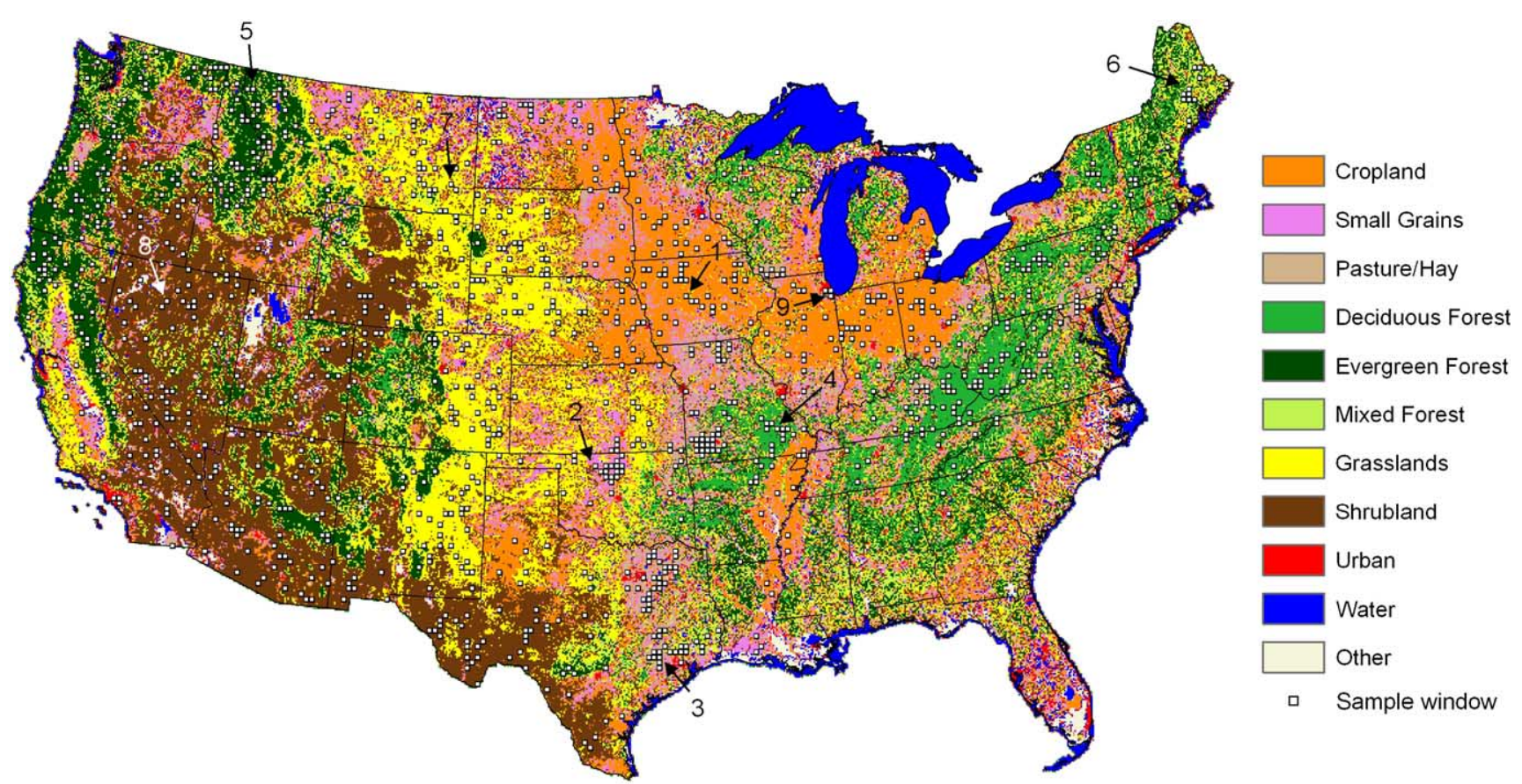

Fig. 1. Locations of AVHRR and MODIS NDVI sample windows within the land cover classes used in this study. The size of the sample windows does represent the $20 \times 20 \mathrm{~km}$ sample size used in this analysis.

PM LST, respectively. Data acquired by the AVHRR sensors onboard the NOAA-16 and NOAA-17 platforms, with ECT (Table 1) of approximately 10:15 AM LST and 2:00 PM LST, respectively, were also analyzed. Comparisons were made between the NDVI data derived from the Terra and NOAA-17 platforms (AM ECT), and Aqua and NOAA-16 platforms (PM ECT). Additional comparisons were made for the Terra and NOAA-16 platforms (AM and PM ECT), and Aqua and
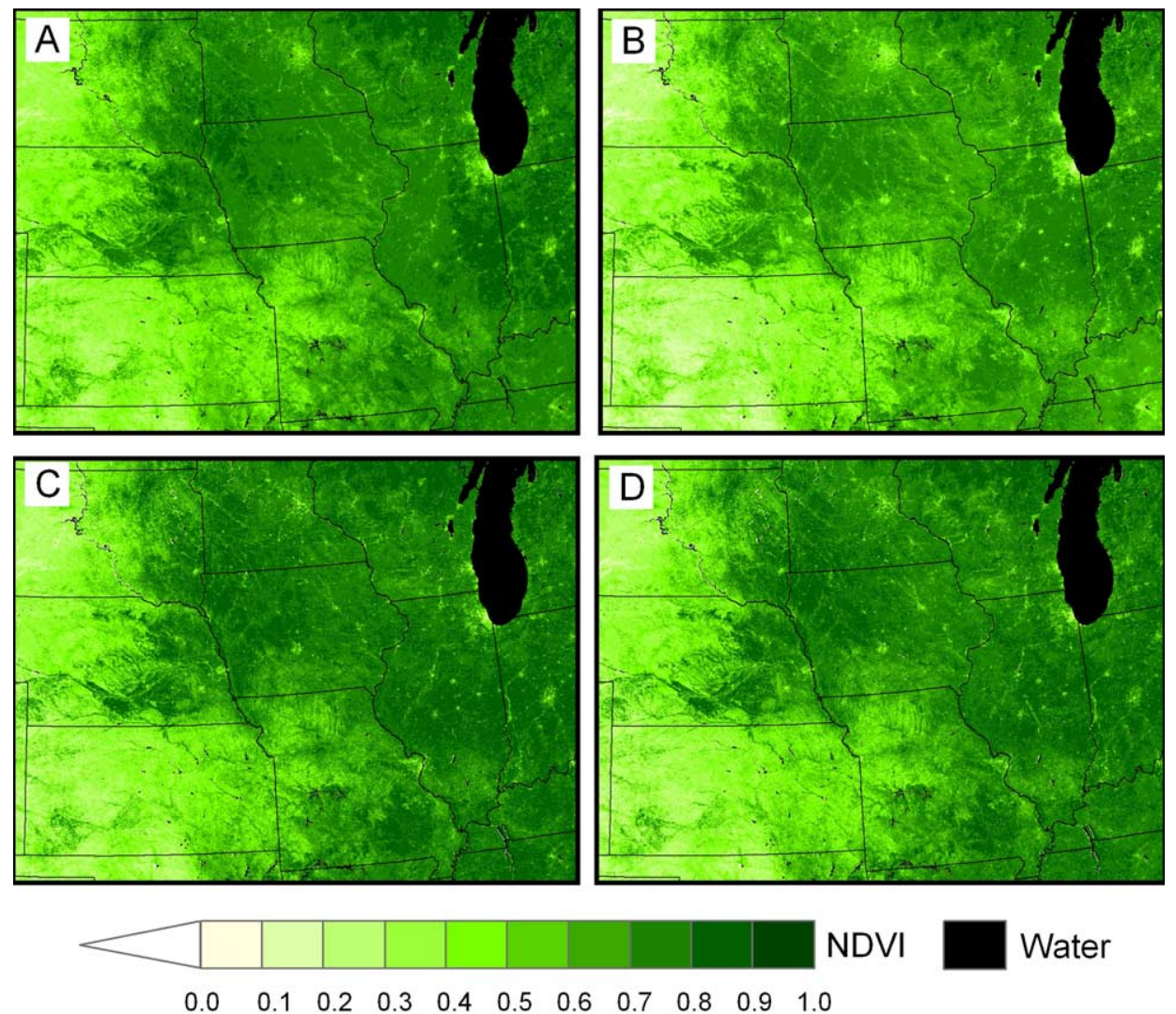

Water

$\begin{array}{lllllllllll}0.0 & 0.1 & 0.2 & 0.3 & 0.4 & 0.5 & 0.6 & 0.7 & 0.8 & 0.9 & 1.0\end{array}$

Fig. 2. NDVI images from 12-27 August 2002 interval displayed for (A) NOAA-16, (B) NOAA-17, (C) Terra MODIS, and (D) Aqua MODIS. 
NOAA-17 platforms (PM and AM ECT). NDVI values were also compared for the Terra and Aqua MODIS, and NOAA-16 and NOAA-17 AVHRR.

Data from NOAA-16 AVHRR and Terra MODIS were compared for all twenty-three 16-day composite intervals of 2002. During 2003 the NOAA-16 AVHRR exhibited data quality problems and only the first 16 composite intervals (1 January-12 September 2003) were available for comparisons. Data for NOAA-17, Terra MODIS, and Aqua MODIS were available for analysis for all 23 intervals of 2003 .

The NDVI data were compared for the nine most areally extensive land cover classes (Fig. 1) that were included in the 21 classes of the 1992 National Land Cover Data Set (Vogelmann et al., 2001). Although an update of this land cover data set is underway (Homer et al., 2004), it is not anticipated to be available for several years. For this analysis, Residential, Commercial, and Urban classes were combined. Twenty by twenty kilometer sample windows of NDVI data were randomly extracted at 1122 sample locations throughout the Conterminous USA (Fig. 1) from the 1-km resolution AVHRR and MODIS data sets. While the samples were randomly selected within the land cover classes, they were the same locations for both the AVHRR and MODIS data sets. To assure homogeneity within the samples, each of the selected samples was required to be occupied by at least $80 \%$ of a single land cover class. Within the 20 by $20 \mathrm{~km}$ sample, only those $1-\mathrm{km}$ grid cells associated with the dominant land cover class were analyzed and compared. The total number of 1-km grid cells sampled per land cover class represented a minimum of $5 \%$ of the total number of $1-\mathrm{km}$ grid cells for that class throughout the conterminous United States.

Additionally, data were extracted for 20 by $20 \mathrm{~km}$ sample windows centered on the same test sites used for comparison of MODIS and AVHRR data in Huete et al. (2002). The NDVI data were extracted from the 23 intervals of the 2002 data for the Terra MODIS and NOAA-16 AVHRR sensors.

\section{Results}

The range of dates for the data that were included in this analysis from 2002 and 2003 are displayed in Table 1. The Terra MODIS and NOAA-16 AVHRR data series were of the greatest duration and the NDVI data of 2001 from these sensors were included in an earlier analysis (Gallo et al., 2004). The NDVI data of the various sensors were compared qualitatively and quantitatively. Example NDVI images for the same composite interval for each of the four sensors examined are displayed in Fig. 2. Generally, the NDVI spatial patterns for the four sensors are very similar. The
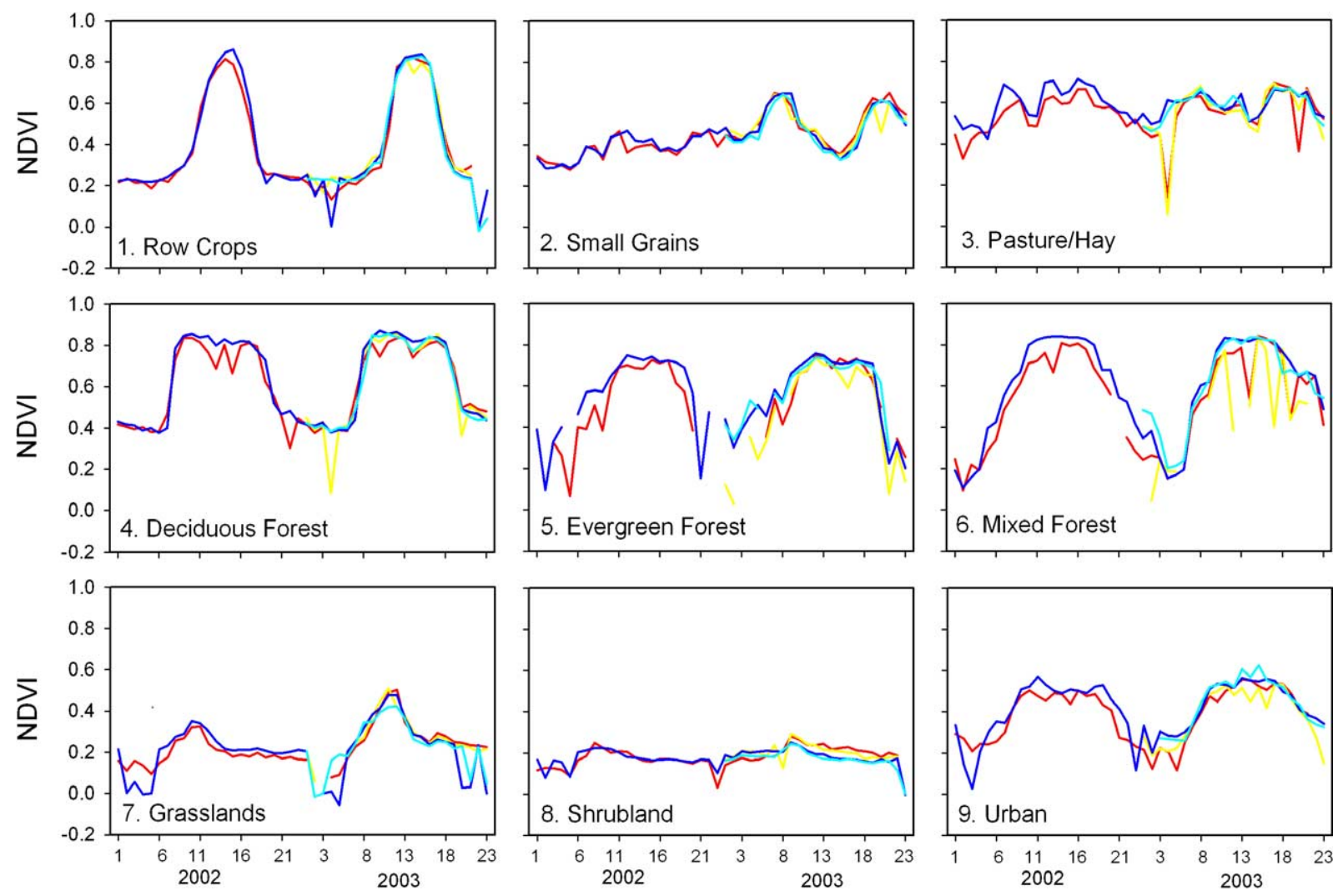

Composite interval

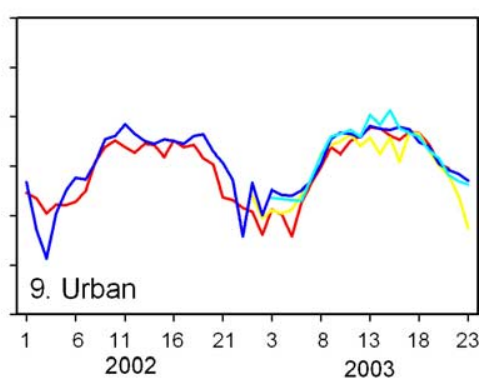

Composite interval

- NOAA-16

NOAA-17

Terra

Composite interval

Fig. 3. Time series of AVHRR and MODIS NDVI for sample locations (numbered 1 through 9) in Fig. 1. Breaks in time series are due to cloud contaminated data. 
Table 2

Results of regression analysis for combined land cover classes included in the analysis of NDVI values from the Terra and Aqua MODIS with values from the AVHRR onboard the NOAA-16 and -17 (N-16 and N-17)

\begin{tabular}{|c|c|c|c|c|}
\hline Analysis & $\begin{array}{l}\beta_{0} \text { estimate and } \\
\text { standard error }\end{array}$ & $\begin{array}{l}\beta_{1} \text { estimate and } \\
\text { standard error }\end{array}$ & $r^{2}$ & $\begin{array}{l}\text { Number of } \\
\text { observations }\end{array}$ \\
\hline Terra/N-16 '02 & $\mathbf{0 . 0 1 1}(0.0016)$ & $\mathbf{1 . 0 4 1}(0.0007)$ & 0.95 & 23,354 \\
\hline Terra/N-16 '03 & $\mathbf{0 . 0 1 2}(0.0010)$ & $\mathbf{1 . 0 2 5}(0.0020)$ & 0.95 & 15,213 \\
\hline Aqua/N-16 '03 & $0.000(0.0043)$ & $1.021(0.0017)$ & 0.96 & 14,946 \\
\hline Terra/N-17 '03 & $-\mathbf{0 . 0 1 6}(0.0011)$ & $1.065(0.0024)$ & 0.89 & 22,223 \\
\hline Terra/Aqua '03 & $\mathbf{0 . 0 0 5}(0.0006)$ & $\mathbf{1 . 0 0 5}(0.0012)$ & 0.97 & 23,803 \\
\hline $\mathrm{N}-16 / \mathrm{N}-17$ '03 & $-\mathbf{0 . 0 1 9}(0.0011)$ & $\mathbf{1 . 0 3 5}(0.0022)$ & 0.94 & 23,356 \\
\hline
\end{tabular}

First sensor listed was considered the dependent variable in the analysis.

${ }^{\mathrm{a}}$ Bold indicates $\beta_{0}$ is significantly different from 0.0 at $p$-value $<0.01$.

${ }^{\mathrm{b}}$ Bold indicates $\beta_{1}$ is significantly different from 1.0 at $p$-value $<0.01$.

NDVI time series of the four sensors were examined (Fig. 3) for sample locations for each of the nine land cover classes included in the analysis (Fig. 1). The time series of the sensors were generally similar with occasional deviations for some of the sensors speculatively due to residual cloud or snow contamination. These results are similar to those from the same locations during 2001 as observed in Gallo et al. (2004).
The relationship between the MODIS and AVHRR NDVI values were evaluated with a linear regression model:

$\mathrm{NDVI}_{\mathrm{M}}=\beta_{0}+\beta_{1}\left(\mathrm{NDVI}_{\mathrm{A}}\right)+\varepsilon$,

where $\mathrm{NDVI}_{\mathrm{M}}$ is the MODIS NDVI, $\mathrm{NDVI}_{\mathrm{A}}$ is the AVHRR NDVI, $\beta_{0}$ is the intercept, $\beta_{1}$ is the slope, and $\varepsilon$ is the random
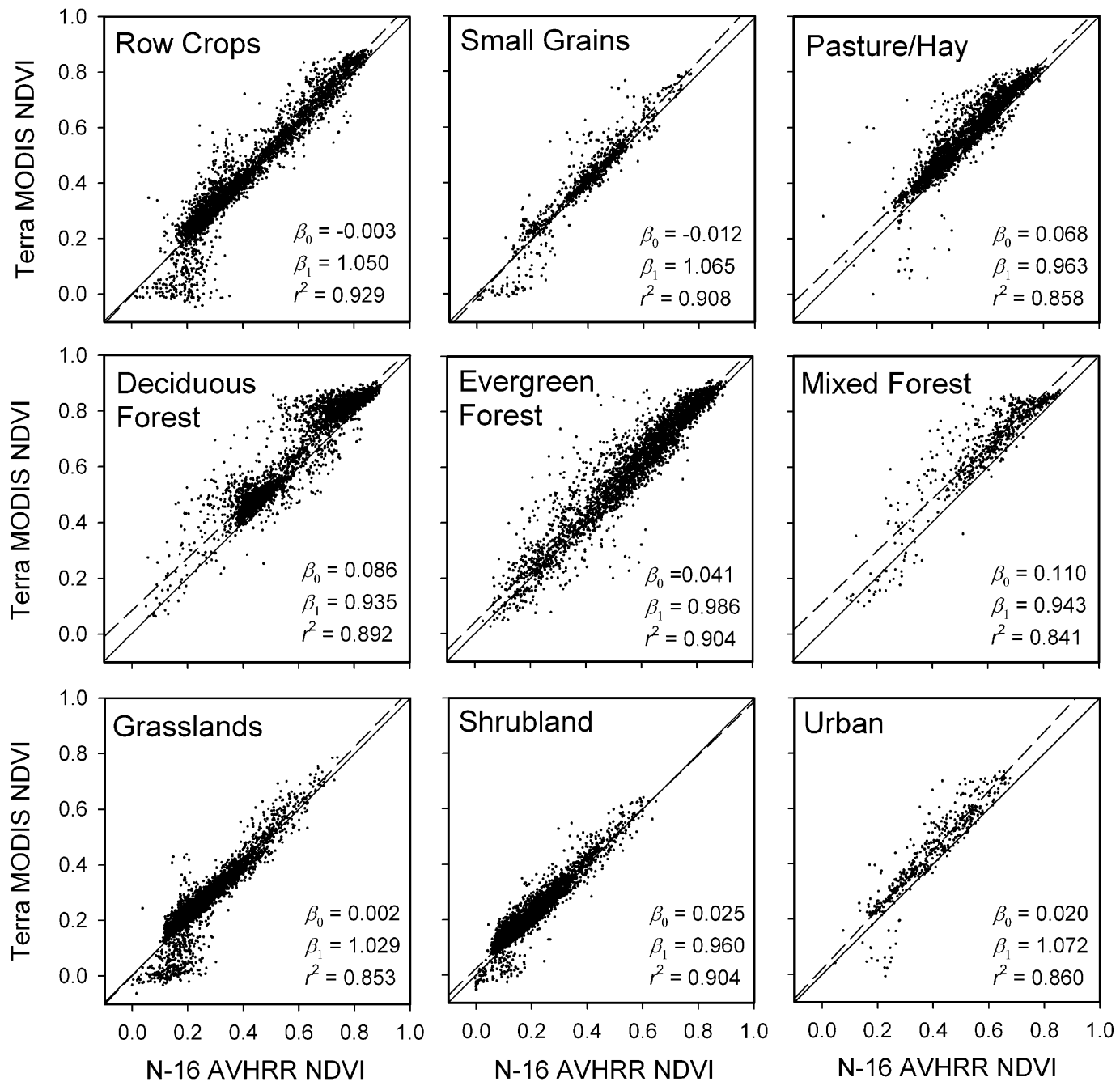

Fig. 4. Terra MODIS and NOAA-16 AVHRR NDVI values for all sample windows and all sample intervals for each of the cover types examined in 2002. Solid lines indicate 1:1 relationships, dashed lines indicate linear relationships. 
error. Regression analyses included (a) samples of individual land cover types and (b) all samples with all land cover types combined to facilitate overall comparisons between the individual sensors. If the compared data sets were identical, i.e., the NDVI values of the MODIS and AVHRR sensors were equal for all samples, the value of the slope would equal 1.0, the intercept would equal 0.0 , and the coefficient of determination $\left(r^{2}\right)$ value would equal 1.0 .

The linear regression relationships (Eq. (1)) between the NDVI values of the various sensor combinations presented in Table 2 were all significant at the $p$-value of $<0.01$ for all individual landcover classes as well as the combined classes. The mean NDVI values for the 20 by $20 \mathrm{~km}$ samples of all locations and composite intervals of the 2002 Terra MODIS and NOAA-16 AVHRR are displayed for each of the examined cover types in Fig. 4. The intercept values for individual land cover classes ranged from -0.01 (Small Grains land cover class) to 0.11 (Mixed Forest). The slope values varied from 0.94 (Deciduous Forest) to 1.07 (Urban) and $r^{2}$ values varied from 0.84 (Mixed Forest) to 0.93 (Row Crops). The results of the combination of all classes for the 2002 Terra MODIS and NOAA-16 AVHRR indicate an intercept (offset) value of 0.01 between the MODIS and AVHRR NDVI values while the slope of the relationship is 1.04 (Table 2). The $r^{2}$ values indicate that more than $95 \%$ of the variation in the MODIS NDVI values is associated with variation in AVHRR NDVI values, with a root mean square error (RMSE) of 0.05 .

The above results were a slight improvement over the results of the same analysis when cloud contaminated pixels were not removed from the analysis $\left(r^{2}=0.93\right.$, RMSE $\left.=0.06\right)$. The results were also similar to the limited analysis (intervals 1-16, 1 January-12 September) of 2003 Terra MODIS and NOAA-16 AVHRR data (Fig. 5) where an intercept value of 0.01 (Table 2) and slope of 1.02 were observed $\left(r^{2}=0.95\right.$, RMSE $=0.06)$. Additionally, the results were similar to those of the comparison of 2001 Terra and NOAA-16 data (intercept of 0.03 , slope of 1.01 , and $r^{2}=0.91$ ) in Gallo et al. (2004).

Data for the PM platforms (NOAA-16 and Aqua) were also limited during 2003 due to data quality problems with the NOAA-16 AVHRR sensor. Over the 16 intervals analyzed (Fig. 6) the slope of the regression analysis (Table 2) was 1.02 and intercept was zero $\left(r^{2}=0.96, \mathrm{RMSE}=0.05\right)$.
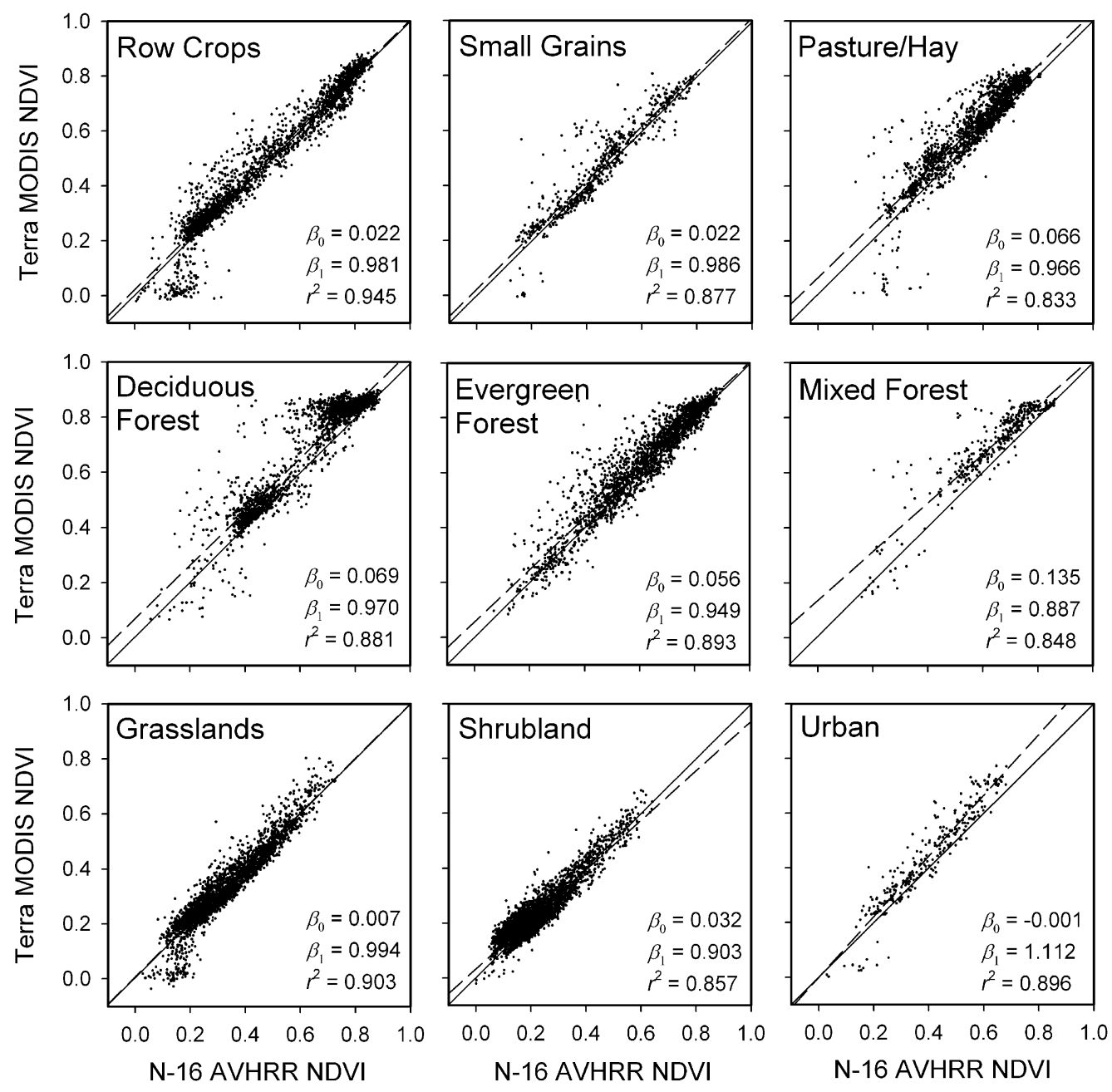

Fig. 5. Terra MODIS and NOAA-16 AVHRR NDVI values for all sample windows and all sample intervals for each of the cover types examined in 2003. Solid lines indicate 1:1 relationships, dashed lines indicate linear relationships. 

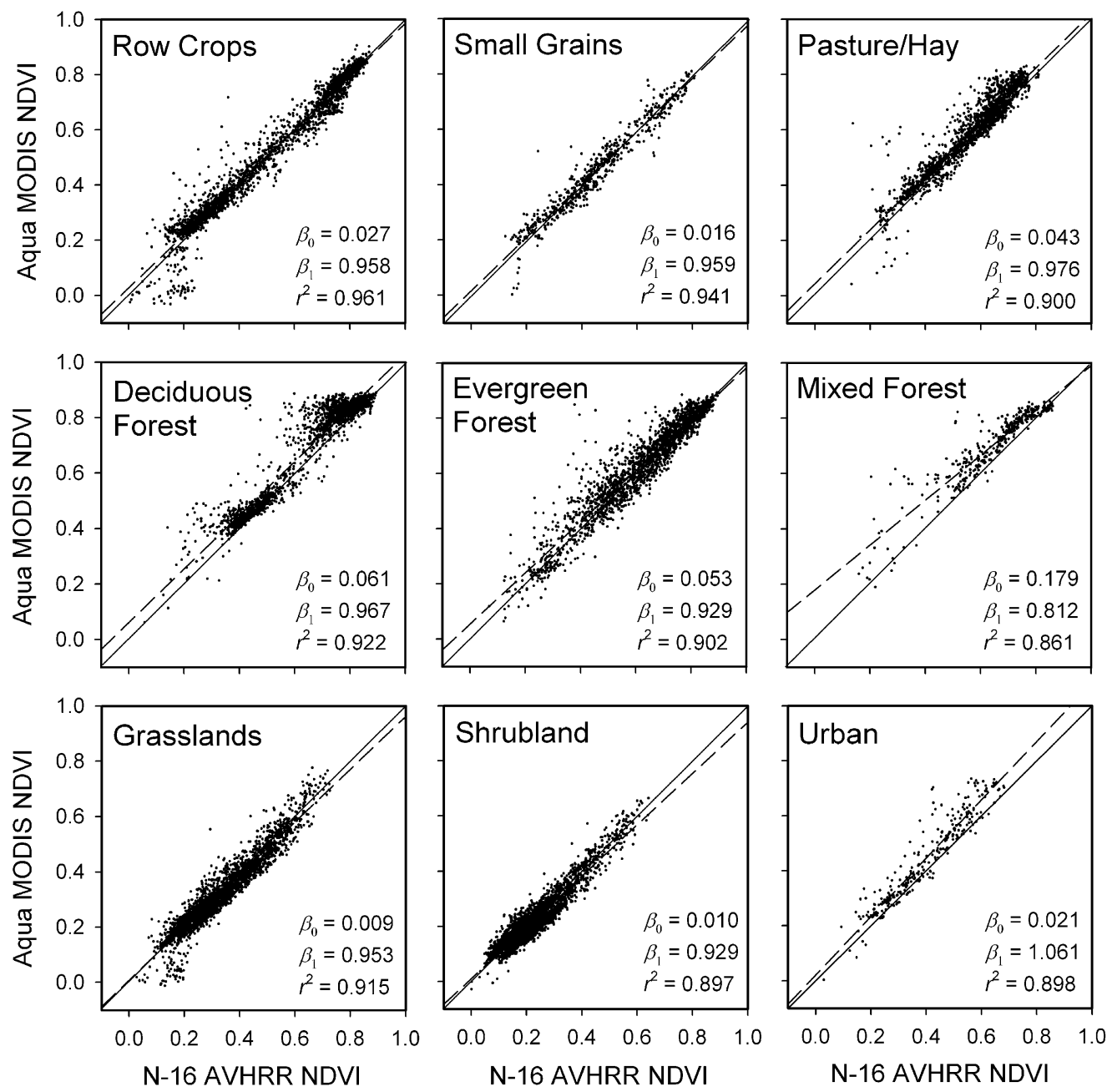

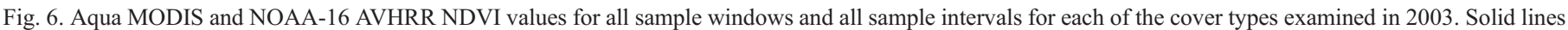
indicate $1: 1$ relationships, dashed lines indicate linear relationships.

Comparisons of the two AM platforms (NOAA-17 and Terra) revealed large variability of the MODIS and AVHRR NDVI values for the Deciduous and Mixed forest classes (Fig. 7). This variability was examined in greater detail and is discussed in the following section.

Data acquired by the two MODIS sensors (AM and PM ECT) were compared (not shown) and generally the NDVI values between the two were very similar (Table 2). Ninetyseven percent of the variation in Terra MODIS NDVI data was associated with the variation in Aqua MODIS NDVI $\left(r^{2}=0.97\right.$, RMSE $=0.04)$. The RMSE value was the lowest observed for the compared sensors. The slope of 1.00 and intercept of zero are also indicative of the similarity between the NDVI values of the two sensors.

The two AVHRR sensors (AM and PM ECT) were also compared (not shown), over the 16 intervals (1 January-12 September) in 2003. The NOAA-16 NDVI values were generally greater than the NOAA-17 values with a slope of 1.04 and an intercept of $-0.019\left(r^{2}=0.94\right.$, RMSE $\left.=0.06\right)$.

Although the land cover class data were combined for the above general comparisons of the sensor NDVI values (and results in Table 2), the slope and intercept values associated with the individual land cover classes were, in general, significantly different from those of the combined class data (Table 2).

\section{Discussion}

Within the various land cover types examined, the Mixed Forest, Pasture/Hay, and Deciduous Forest classes generally exhibited the lowest $r^{2}$ values. The NOAA-17 AVHRR data in particular exhibits a wide range in NDVI values (Fig. 7) for the Deciduous Forest classes at Terra MODIS values greater than 0.7. While the NOAA-16 AVHRR data for the Deciduous Forest class (Figs. 4-6) displayed a high level of variation in NDVI at Terra and Aqua MODIS values greater than 0.7, it was not as great as that displayed for the NOAA-17 data (Fig. 7). Additional analysis of the NOAA-17 AVHRR data revealed that the Deciduous Forest class was not the contributor to the variation in the AVHRR data. Rather, the geographic location of the class, primarily in the Northeastern and Middle Atlantic portions of the USA (Fig. 1), contributed to the lower values of AVHRR-derived NDVI compared to the MODIS NDVI values. The NOAA-17 AVHRR data acquired for several 16-day intervals included residual clouds, not identified as clouds with the CLAVR algorithms, for this portion of the USA during 

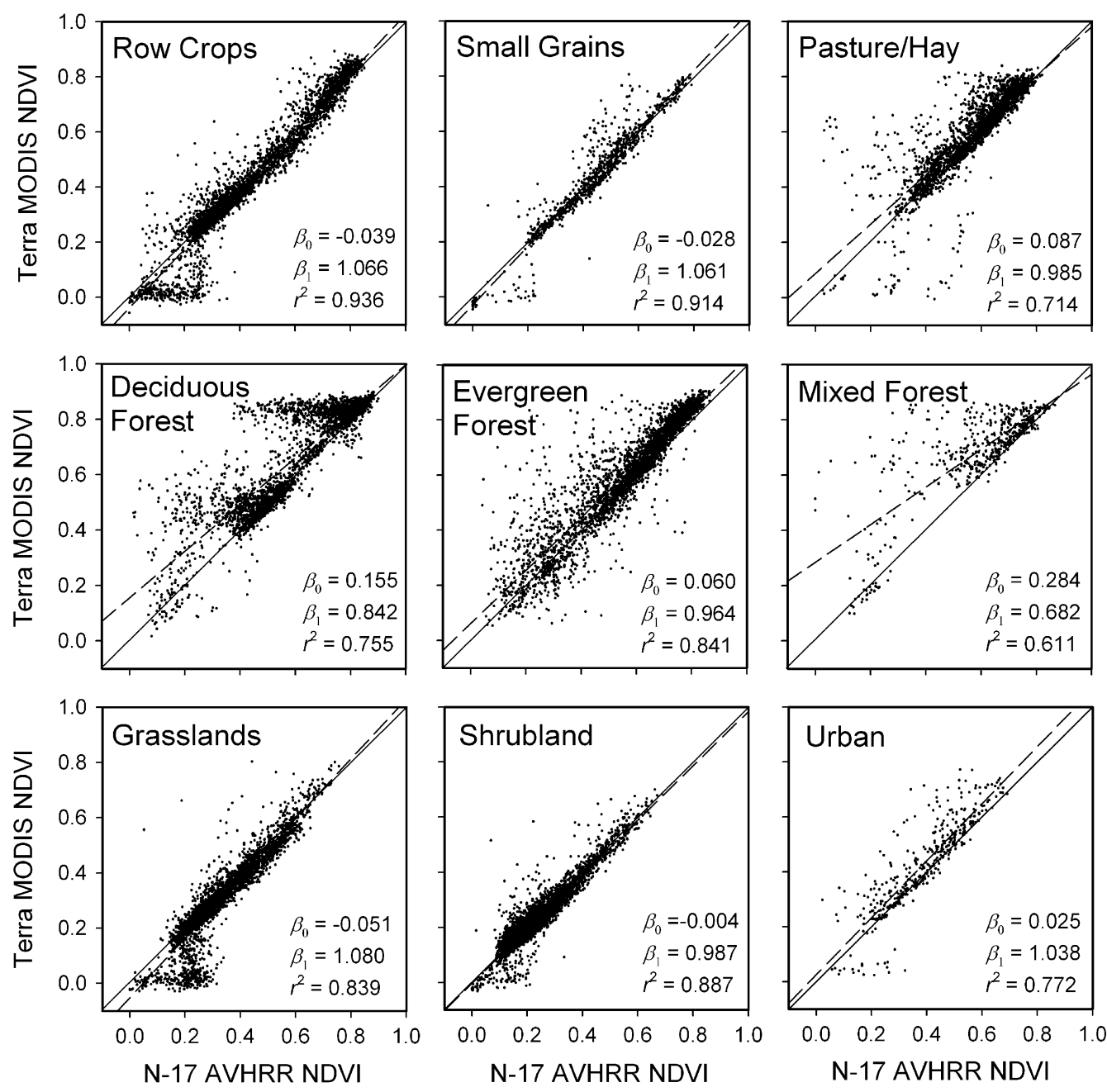

Fig. 7. Terra MODIS and NOAA-17 AVHRR NDVI values for all sample windows and all sample intervals for each of the cover types examined in 2003. Solid lines indicate 1:1 relationships, dashed lines indicate linear relationships.

several composite intervals of the summer of 2003 (Fig. 8). The presence of residual clouds in this data may have been a result of the application of the CLAVR algorithms to an NDVI composited AVHRR data set, as previously mentioned, that did not include the spatial algorithms of CLAVR that need to be applied on an individual scene or orbit basis.

The residual clouds resulted in lower NDVI values for the AVHRR data, while the MODIS data acquired was not influenced by cloud contamination of the data. Apparently, 1 or 2 days with marginally cloud-free observations over the regions that included Deciduous Forest sample targets were not processed for the AVHRR data due to extreme off-nadir view angles or sufficient cloud contamination of the images to prohibit ground control point selection for the data registration process.

The variation in AVHRR-derived NDVI values at the lower range of values (e.g., Grassland and Row Crops classes, Fig. 7) was also examined. The available MODIS snow cover mask was used to identify areas of snow cover and remove them from the analysis. The removal of those samples identified as snow removed the observed variation in the lower range of AVHRR values displayed in Fig. 7 for the Grassland and Row Crop classes. Thus, the variation in MODIS and AVHRR NDVI values of the Grassland and Row Crop classes at the low range of NDVI values (Fig. 7) is attributed to the presence of snow cover.

Overall, these results appear consistent with other studies that have included comparisons of MODIS and AVHRR NDVI data, when differences in the data utilized are considered. Terra MODIS NDVI values were generally greater than NOAA-14 AVHRR NDVI values in an analysis over Senegal (Fresholt, 2004), South Florida (Venturini et al., 2004), and the Southern Great Plains of the United States (Trishchenko et al., 2002). In a simulation of MODIS and AVHRR data (Steven et al., 2003), the MODIS NDVI data were also found to be greater than the AVHRR NDVI data.

Terra MODIS and NOAA-14 AVHRR NDVI values observed in 2000 were included in comparisons at several sites that included diverse vegetation and climate conditions (Huete et al., 2002). The MODIS and AVHRR NDVI values were found to be "nearly identical" for the arid and semi-arid test sites. The AVHRR NDVI values were observed to be significantly lower than the MODIS NDVI values during wet intervals of the growing season at the non-arid test sites. Overall, the dynamic range of the MODIS NDVI values was found to be $50 \%$ greater 

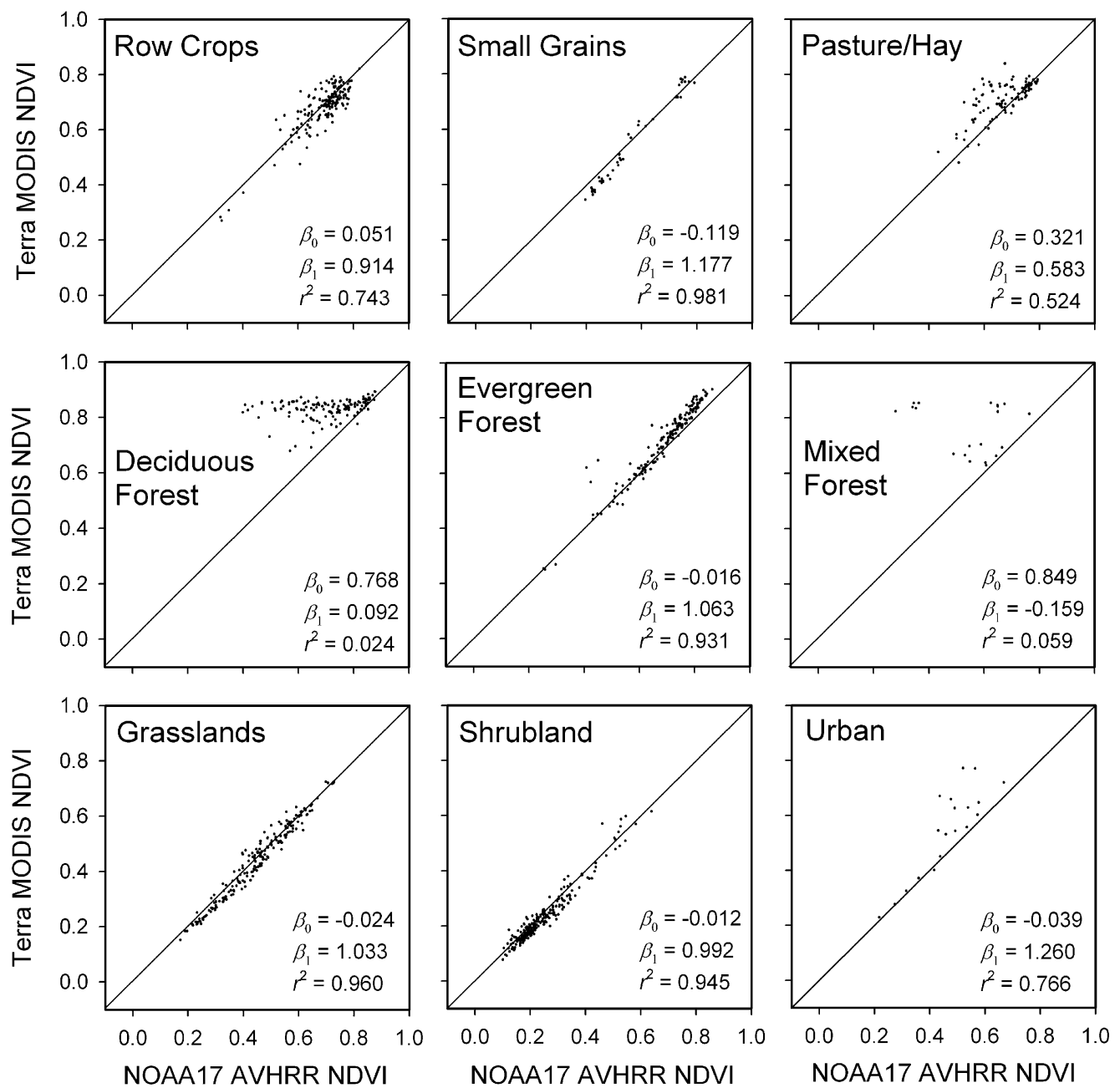

Fig. 8. Terra MODIS and NOAA-17 AVHRR NDVI values for all sample windows, for the 26 June-11 July 2003 composite interval, for each of the cover types examined. Solid lines indicate 1:1 relationships.

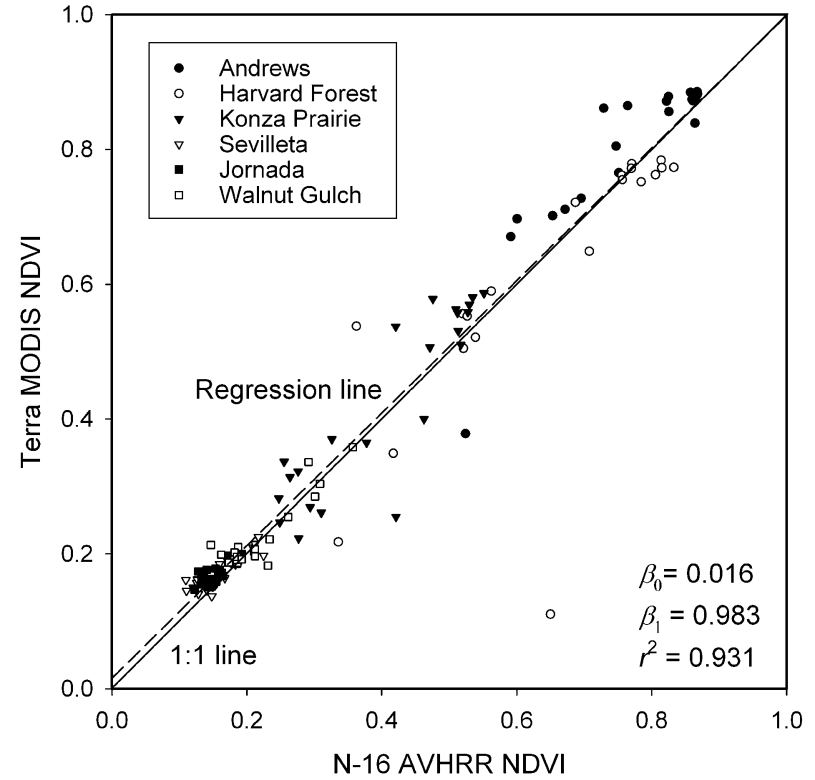

Fig. 9. Terra MODIS and NOAA-16 AVHRR NDVI values for 131 observations during 2003 at the test sites used in an analysis of 2000 data (NOAA-14 and Terra MODIS) by Huete et al. (2002). Solid lines indicate 1:1 relationships, dashed lines indicate linear relationships. than that of the AVHRR NDVI values. These differences in the MODIS and AVHRR values are primarily attributed to the wider bandwidth of the NIR channel on the AVHRR, which is subject to water vapor contamination. The AVHRR data used in the above studies did not include water vapor adjustments.

The water vapor adjusted NDVI values used in this study (NOAA-16 AVHRR) and Terra MODIS NDVI values for the test sites examined in Huete et al. (2002) were compared. Huete et al. (2002) observed a reduced dynamic range in the NOAA-14AVHRR data compared to the MODIS NDVI data

Table 3

NDVI values at $5 \%, 50 \%$, and $95 \%$ cumulative frequencies for NOAA-16 (N-16), NOAA-17 (N-17), Terra, and Aqua platforms

\begin{tabular}{lllll}
\hline & Year & $5 \%$ & $50 \%$ & $95 \%$ \\
\hline N-16 & 2002 & 0.11 & 0.37 & 0.79 \\
Terra & 2002 & 0.12 & 0.40 & 0.83 \\
N-16 & 2003 & 0.14 & 0.41 & 0.81 \\
N-17 & 2003 & 0.12 & 0.40 & 0.83 \\
Terra & 2003 & 0.10 & 0.40 & 0.82 \\
Aqua & 2003 & 0.06 & 0.40 & 0.83 \\
\hline
\end{tabular}

${ }^{\text {a }} \mathrm{N}-16$ data only available for 1 Jan-12 Sep 2003 interval. 
and "significant atmosphere-induced scatter" in the exhibited relationship between the MODIS and AVHRR data. The water vapor adjusted NDVI (NOAA-16) used in this study exhibited values very similar to the Terra MODIS NDVI values (Fig. 9) at the locations included in the analysis of Huete et al. (2002). The dynamic range appears nearly identical for these two sensors and the AVHRR NDVI values were associated with over $93 \%$ of the variation in the MODIS NDVI values.

The results of the regression analysis of this study (Table 2), which includes water vapor adjustments, indicate that the expected values of the Terra and Aqua MODIS NDVI data are only slightly greater than the NOAA-16 AVHRR NDVI values. Similarly, the results for the two AM platforms indicate that the Terra MODIS NDVI values would be expected to be slightly greater than the NOAA-17 AVHRR NDVI values.

The NDVI values associated with the 5\%,50\%, and $95 \%$ cumulative frequencies of the NDVI values were examined for the MODIS and AVHRR data included in this study (Table 3). Other than the slightly lower value for the Aqua MODIS at the $5 \%$ cumulative frequency, the other values were all similar at the $50 \%$ and $95 \%$ levels. The overall similarity in the dynamic range of NDVI values for the MODIS and AVHRR is considered to be a result of the water vapor adjustments applied to the AVHRR data.

Although the AVHRR NDVI values were highly associated with the variation in MODIS NDVI values when the cover types included in this study were combined, the results suggest that the relationship between the AVHRR and MODIS NDVI values can vary with land cover type.

\section{Conclusions}

Although differences existed in several factors that might influence the composite NDVI values, the 16-day composite NDVI values observed with the Terra and Aqua MODIS, and NOAA-16 and NOAA-17 AVHRR, were quite similar when sampled over similar time intervals, spatial areas, and land cover types. Additional improvements to the relationships in NDVI might be expected with aerosol correction of the AVHRR data and adjustments for differences between the sensors in solar and satellite viewing geometry and spectral response functions of the sensors, which were beyond the scope of this analysis. The prospects appear good for future efforts to reprocess AVHRR data sets with a goal of continuity of an NDVI product through time. With inclusion of cloud identification, water vapor corrections, and additional data quality assurance information similar to MODIS (e.g., cloud shadows and snow cover), historical AVHRR NDVI data may be useful as a climatological tool in comparisons with future sensor data. NDVI data derived from AVHRR sensors should continue to be directly compared to NDVI derived from MODIS, as well as future data acquired by the operational VIIRS sensors. In addition to analysis of composite products, comparisons should be made for the individual red and NIR band data used to compute NDVI for data acquired on single dates. These studies would optimally include analysis of the influence of bi-directional reflectance and spectral response functions on the individual bands as well as NDVI data.

\section{Acknowledgements}

This study was partially supported by the National Polarorbiting Operational Environmental Satellite System (NPOESS) Integrated Program Office's (IPO) Internal Government Studies Program. The manuscript contents are solely the opinions of the author(s) and do not constitute a statement of policy, decision, or position on behalf of NOAA or the U.S. Government. The authors wish to acknowledge the valuable contributions made by the reviewers of this manuscript.

\section{References}

Defelice, T. P., Lloyd, D., Meyer, D. J., Baltzer, T. T., \& Piraino, P. (2003). Water vapour correction of the daily $1 \mathrm{~km}$ AVHRR global land dataset: Part I validation and use of the water vapour input field. International Journal of Remote Sensing, 24, 2365-2375.

El Saleous, N., Vermote, E., \& Roger, J. -C. (1994). Operational atmospheric correction of AVHRR visible and near infrared data. Proceedings of IGARRS '94: International Geoscience and Remote Sensing Symposium, August 8-12, 1994, California Institute of Technology, Pasadena, CA. Piscataway, NJ: Institute of Electrical and Electronics Engineers.

Fresholt, R. (2004). Earth observation of vegetation status in the Sahelian and Sudanian West Africa: Comparison of Terra MODIS and NOAA AVHRR satellite data. International Journal of Remote Sensing, 25, $1641-1659$.

Gallo, K., Ji, L., Reed, B., Dwyer, J., \& Eidenshink, J. (2004). Comparison of MODIS and AVHRR 16-day normalized difference vegetation index composite data. Geophysical Research Letters, 31, L07502, doi:10.1029/ 2003 GL019385.

Gao, X., Huete, A. R., \& Didan, K. (2003). Multisensor comparisons and validation of MODIS vegetation indices at the semiarid Jornada Experimental Range. IEEE Transactions on Geoscience and Remote Sensing, 41, $2368-2381$.

Gitelson, A., \& Kaufman, Y. (1998). MODIS NDVI optimization to fit the AVHRR data series - spectral considerations. Remote Sensing of Environment, 66, 343-350.

Homer, C., Huang, C., Yang, L., Wylie, B., \& Coan, M. (2004). Development of a 2001 National Landcover Database for the United States. Photogrammetric Engineering and Remote Sensing, 70, 829-840.

Huete, A., Didan, K., Miura, T., Rodriguez, E. P., Gao, X., \& Ferreira, L. G. (2002). Overview of the radiometric and biophysical performance of the MODIS vegetation indices. Remote Sensing of Environment, 83, $195-213$.

Kogan, F. N. (1997). Global Drought Watch from Space. Bulletin of the American Meteorological Society, 78, 621.

Myneni, R., Tucker, C., Asrar, G., \& Keeling, C. (1998). Interannual variations in satellite-sensed vegetation index data from 1981 to 1991. Journal of Geophysical Research, 103, 6145-6160.

Nemani, R. R., Keeling, C. D., Hashimoto, H., Jolly, W. M., Piper, S. C., et al. (2003). Climate-driven increases in global terrestrial net primary production from 1982 to 1999. Science, 300, 1560-1563.

Potter, C., Tan, P. -N., Steinbach, M., Klooster, S., Kumar, V., et al. (2003). Major disturbance events in terrestrial ecosystems detected using global satellite data sets. Global Change Biology, 9, 1005-1021.

Steven, M. D., Malthus, T. J., Baret, F., Xu, H., \& Chopping, M. J. (2003). Intercalibration of vegetation indices from different sensor systems. Remote Sensing of Environment, 88, 412-422.

Stowe, L. D., Davis, P., \& McClain, A. (1999). Scientific basis and initial evaluation of the CLAVR-1 global clear/cloud classification algorithm for 
the advanced very high resolution radiometer. Journal of Atmospheric and Oceanic Technology, 16, 656-681.

Teillet, P. M. (1991). Radiometric and atmospheric correction procedures for AVHRR preprocessing in the solar reflective channels. Proceeding 5th Colloquium, Mesures physiques et signatures en télédétection/Physical Measurements and Signatures in Remote Sensing, Courchevel, France, January 14-18, No ESA SP-319, 1991 (pp. 101-104).

Trishchenko, A., Cihlar, J., \& Li, Z. (2002). Effects of spectral function on surface reflectance and NDVI measured with moderate resolution satellite sensors. Remote Sensing of Environment, 81, 1-18.

Tucker, C. J., Slayback, D. A., Pinzon, J. E., Los, S. O., Myneni, R. B., \& Taylor, M. G. (2001). Higher northern latitude normalized difference vegetation index and growing season trends from 1982 to 1999. International Journal of Biometeorology, 45, 184-190.
Venturini, V., Bisht, G., Islam, S., \& Jiang, L. (2004). Comparison of evaporative fractions estimated from AVHRR and MODIS sensors over South Florida. Remote Sensing of Environment, 93, 77-86.

Vogelmann, J. E., Howard, S. M., Yang, L., Larson, C. R., Wylie, B. K., \& Van Driel, J. N. (2001). Completion of the 1990's National Land Cover Data Set for the conterminous United States. Photogrammetric Engineering and Remote Sensing, 67, 650-662.

Zhou, L., Tucker, C. J., Kaufmann, R. K., Slayback, D., Shabanov, N. V., \& Myneni, R. B. (2001). Variations in northern vegetation activity inferred from satellite data of vegetation index during 1981 to 1999. Journal of Geophysical Research, 106, 20069-20083. 